\title{
Editorial
}

\section{Wind Generation Systems including Energy Storage}

\author{
Lei Chen, ${ }^{1}$ Li Ren, ${ }^{2}$ Lin Zhu, ${ }^{3}$ Tao Wang, ${ }^{4}$ and Yuanzheng $\mathrm{Li}^{5}$ \\ ${ }^{1}$ School of Electrical Engineering, Wuhan University, Wuhan 430072, China \\ ${ }^{2}$ State Key Laboratory of Advanced Electromagnetic Engineering and Technology, Huazhong University of Science and Technology, \\ Wuhan 430074, China \\ ${ }^{3}$ Department of Electrical Engineering and Computer Science, University of Tennessee, Knoxville, TN 37996, USA \\ ${ }^{4}$ Waseda Research Institute for Science and Engineering, Waseda University, Tokyo 169-8555, Japan \\ ${ }^{5}$ School of Electrical and Electronic Engineering, Nanyang Technological University, Singapore 639798
}

Correspondence should be addressed to Lei Chen; chen_lei@whu.edu.cn

Received 10 September 2017; Accepted 13 September 2017; Published 9 November 2017

Copyright (C) 2017 Lei Chen et al. This is an open access article distributed under the Creative Commons Attribution License, which permits unrestricted use, distribution, and reproduction in any medium, provided the original work is properly cited.

In recent years, the combined application of wind generation and energy storage has received more and more attention around the world. Technically, wind generation systems including energy storage can offer many benefits, such as power oscillation damping, economic energy dispatch, voltage-frequency stabilization, and fault ride-through (FRT) capability enhancement. This special issue is to provide a platform for presenting the latest research results on wind generation systems including energy storage.

This special issue compiles 8 original researches that describe the technical evaluation, economic performance, low-voltage ride-through (LVRT) capability, optimal capacity, numerical simulation, and experimental verification of wind generation systems including energy storage.

There are three papers on the performance evaluation of wind generation systems. The paper by D. H. Didane et al. conducts the evaluation of wind energy potential as a power generation source in Chad, and a comprehensive wind database and wind map are presented. The paper by H.-K. Chen et al. studies the economic evaluation of three available solutions for promotion of wind power integration, and here the pumped hydrostorage (PHS), heat storage (HS), and electric boiler (EB) are selected to do a detailed comparison. From the given results, the HS requires the least investment and has good performance of coal-saving when accommodating the same amount of curtailed wind power. And the EB has the greatest potential for wind power integration with huge growth of installed capacity of wind power in the future. In the paper by M. Majidniya et al., enhancing the stability of the horizontal axis wind turbine (HAWT) system is regarded as a research objective, and both of a pumped hydrostorage (PHS) and extra produced electricity are taken into account. The economic analysis of them is performed, and some preliminary discussions on the electricity price and the real interest rate are conducted.

There are two papers on the transient characteristics of wind generation systems. The paper by X. Zhou et al. proposes the use of a superconducting magnetic energy storage (SMES) to improve the LVRT capability of the doubly fed induction generators- (DFIGs-) based wind turbine systems. The demonstrated results show that utilizing the SMES in the rotor side can help to produce a desired output voltage and absorb excess energy under faults, so as to enhance the robustness of wind power generation to a certain extent. In the paper by $\mathrm{H}$. He et al., wind power is transmitted through a voltage source converter- (VSC-) based high voltage direct current (HVDC) system, and the researches on overvoltage calculation and insulation coordination are carried out. It is found that the most serious overvoltage is caused by the fault clearing of the DC breaker, and further the insulation coordination for the overhead lines is addressed in accordance with the calculated overvoltage level.

In addition, the paper by $\mathrm{X}$. Liu et al. investigates the optimal sizing for wind/PV/battery system by use of Fuzzy $c$-means clustering with self-adapted cluster number. Meanwhile, a feasible power balance strategy is introduced 
to guide the optimization process with the genetic algorithm, and the optimal configuration is established by considering the minimized cost, reliability, and environmental factors.

Finally, there are two papers on the simulation and experiment of wind generation systems. The paper by J. M. Garcia-Bravo et al. presents the variable ratio hydrostatic transmission simulator for optimal wind power drivetrains. According to the simulation and experimental results, the electrical power output can be regulated further if an energy storage device is used to absorb voltage spikes produced by abrupt changes in wind speed or wind direction. In the paper by I. Marchevsky and V. Puzikova, a software package is developed for numerical simulation of wind turbine rotors autorotation, and the modified LS-STAG level-set/cut-cell immersed boundary method is used. From the simulation analyses, it is verified that the computational results are in good qualitative agreement with the experimental data.

It is hoped that these papers enable enriching our readers and offer useful information about the current contributions and potential challenges related to the wind generation systems including energy storage.

\author{
Lei Chen \\ Li Ren \\ Lin Zhu \\ Tao Wang \\ Yuanzheng $L i$
}




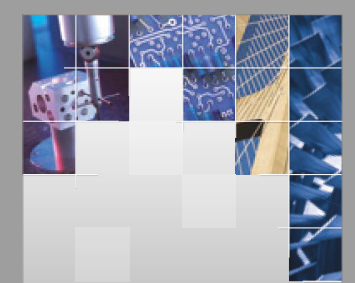

\section{Enfincering}
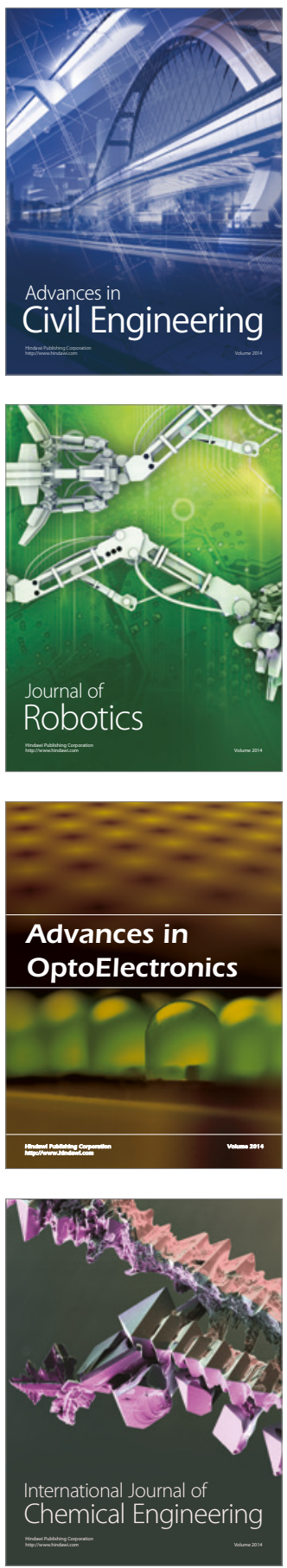

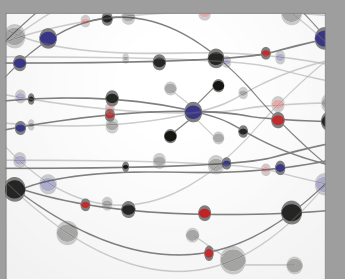

The Scientific World Journal

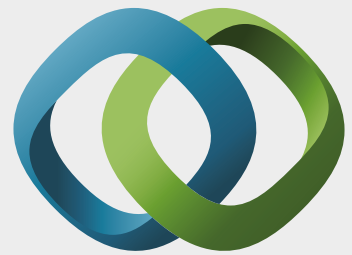

\section{Hindawi}

Submit your manuscripts at

https://www.hindawi.com
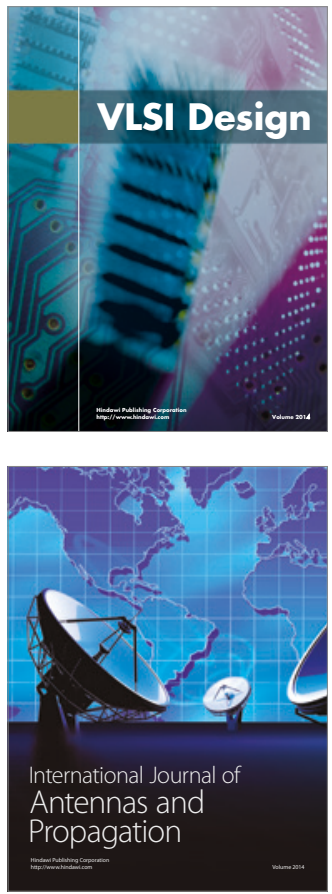

\section{Rotating}

Machinery
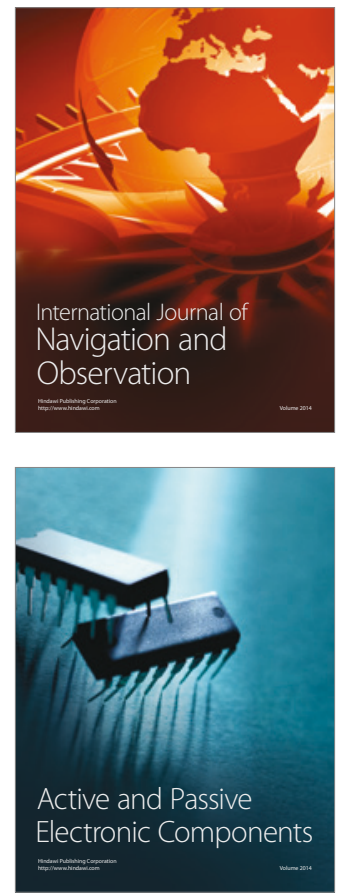
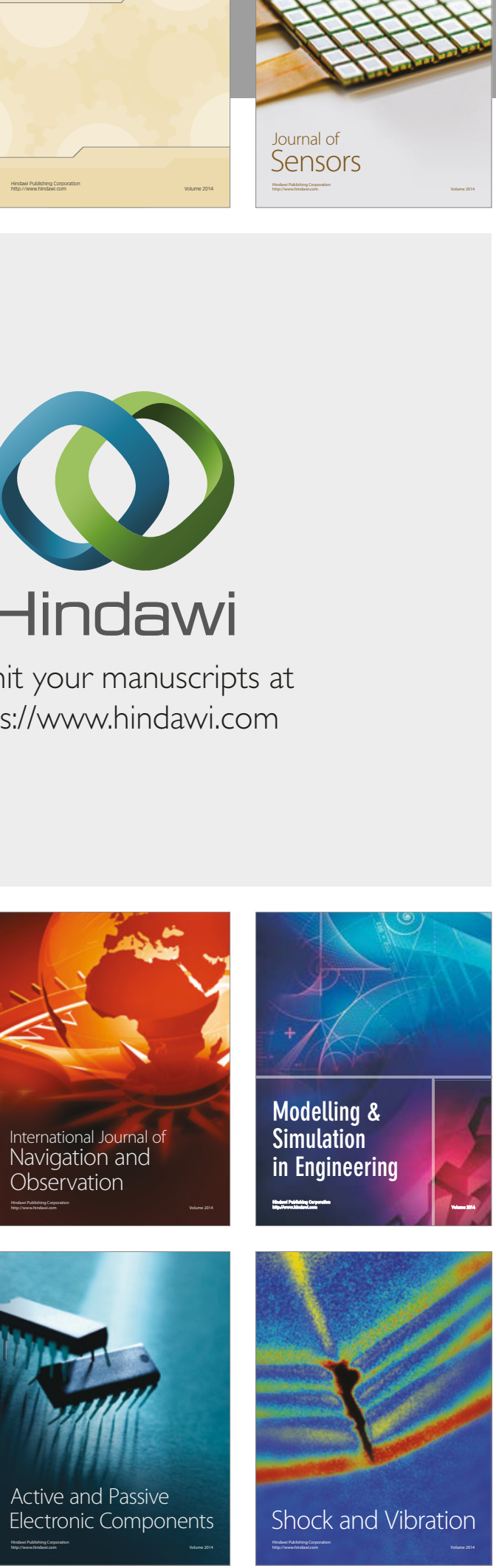
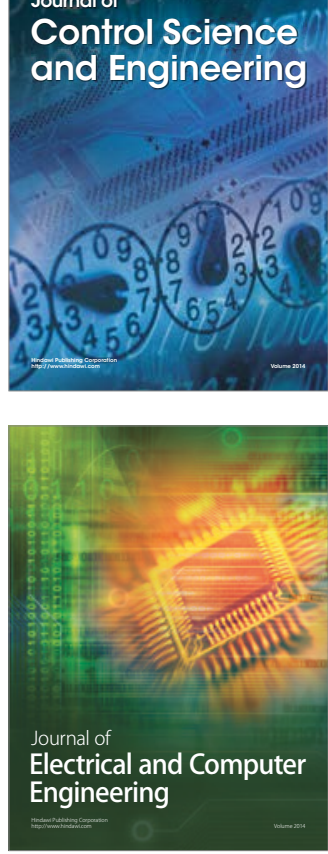

Distributed

Journal of

Control Science

and Engineering
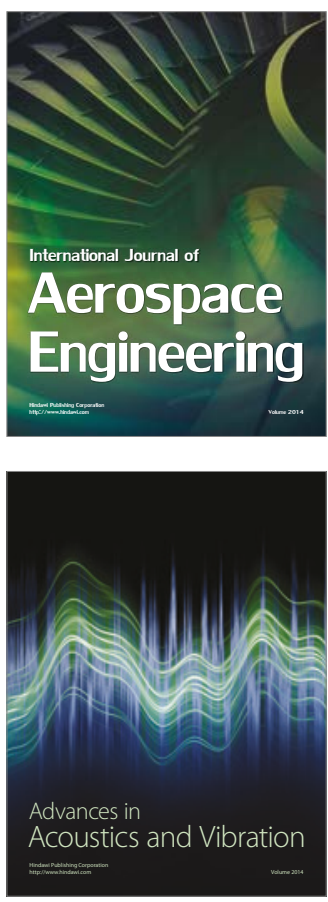

Sensor Networks 